\title{
Climate change and urban flooding: implications for nigeria's built environment
}

\begin{abstract}
Climate change, which is the result of global warming relates to seasonal changes occurring in a given geographical area over a long period of time. Issues of climate change have in recent times dominated discussions in many local and international fora in view of its perceived devastating consequences affecting rainfall patterns, storms and droughts, growing seasons, humidity and sea levels. The inundation of land due to changes in local climate can pose a serious challenge. This paper therefore looks at urban flooding as one of the environmental problems associated with extreme weather events arising from climate change and discusses its impact on the built environment. It highlights appropriate risk management initiatives that can be implemented to mitigate the general impacts of flooding in Nigeria's built environment.
\end{abstract}

Keywords: climate change, global warming, sea level, flooding, built environment
Volume I Issue I - 2016

\author{
Gabriel Igbe Akeh,' Alfred D Mshelia ${ }^{2}$ \\ 'Department of Estate Management and Valuation, Nigeria \\ ${ }^{2}$ Department of Geography, Adamawa State University Mubi, \\ Nigeria
}

Correspondence: Gabriel Igbe Akeh, Department of Estate Management and Valuation, School of Environmental Studies Ramat Polytechnic Maiduguri, Borno state, Nigeria, Email alfredmshelia@yahoo.com

Received: October 12, 2016 | Published: November 02, 2016

\section{Introduction}

Although climate change issues have been discussed since the early $19^{\text {th }}$ Century, it only emerged as an international policy concern during the 1970s and 1980s. And since then, there has been an increasing global concern about its potential impacts on the human environment. ${ }^{1,2}$

The changing climate is attributed to the warmer global temperatures in the atmosphere due to the build-up of carbon-dioxide and other greenhouse gases (GHGs) induced largely by anthropogenic factors. Such factors include urbanization, land use and industrial growth.

Although a warming trend is anticipated globally as indicated by the $^{3}$ Intergovernmental Panel on Climate change (IPCC), different areas around the world will experience different specific changes in their climate, which will have unique impacts on their local environments. Projections from the IPCC in $2007^{4}$ revealed that under a business as usual scenario, greenhouse gas emissions could rise by $25-30 \%$ by 2030 , which could make the earth to warm by $3^{\circ} \mathrm{C}$ during this Century.

As a result of global warming, the type, frequency and intensity of extreme weather events such as tropical cyclones, floods, droughts, and heavy precipitation events are expected to rise even with relatively small average temperature increases with many accompanying consequences. Posited ${ }^{1}$ that the most obvious risk associated with climate change comes from the likely increase in the number and intensity of extreme weather events such as rainstorms, cyclones, hurricanes and drought. According to him, climate change could have potential impact on flooding in three ways; from the sea (through sea levels and storm surges), from prolonged and heavier rainfall and from changes that increase river flows.

Recent studies have already shown that flooding is now more frequent and intense and often occurring in locations previously not at risk. ${ }^{2,5}$ According to the United Nations Framework Convention on Climate Change (UNFCCC), more of the world's population will continue to face increased risk of floods, droughts and water scarcity. Sea level risk will lead to inundation of coasts worldwide with small island states possibly facing complex inundation and people living with the constant threat of tropical cyclones increasing in severity and frequency with all associated risks to life and livelihoods.

While many countries of the world have began to initiate adaptation and mitigation measures to help people cope with the potential impacts of climate change, ${ }^{6}$ most developing countries including Nigeria are yet to do so despite concerns that they are going to be the worst-hit by the impact of climate change. ${ }^{?}$

The objective of this paper therefore to evaluate specific impacts of climate-induced flooding on the urban environment of Nigeria and make appropriate recommendations with emphasis on adaptation ${ }^{8}$ and mitigation measures so as to reduce the vulnerability of the country to the potential future impacts of climate change.

\section{Global warming and climate change}

Global warming is the increase in the earth's average temperature due to the build-up of carbon dioxide $\left(\mathrm{CO}_{2}\right)$ and other green house gases (GHGs) in the atmosphere from anthropogenic activities. Global warming therefore causes climate change. As levels of $\mathrm{CO}_{2}$ and GHGs increase, more heat is "trapped" and global temperatures rise. This causes significant changes in the timing and length of the seasons as well as the amount of precipitation" (IPCC, 2007).

According to IPCC (2007), emissions of GHGs and aerosols due to human activities continue to alter the atmosphere in ways that will continue to affect the climate. These gases are known to remain in the atmosphere for a long time usually decades to millennia.

The sources of $\mathrm{CO}_{2}$ and GHGs can be traced to land use changes initiated through processes of urbanization and deforestation and from burning of fossil fuels used in transportation, industrial processes, heating and cooling of buildings, transport and manufacture of 
cement and other goods. These activities distort the carbon cycle and initiates climate change processes. These processes involves a variety of changes including higher surface temperatures, changes to the hydrological cycle including more frequent heavy rains and less total precipitation in some regions, more intense and perhaps more frequent tropical storms and more "El-Nino" conditions. The warmer temperatures lead to thermal expansion of ocean waters and melting of glaciers and ice on land, which causes the sea-level to rise. Higher sea levels and more intense tropical storms cause higher storm surges. ${ }^{10}$

The global anthropogenic GHG emissions, sources and contribution are shown below:
i. Energy supply
$25 \%$
ii. Industry
$19.4 \%$
iii. Forestry
$17.4 \%$
iv. Agriculture
$13.5 \%$
v. Transport
$13.1 \%$
vi. Residential and commercial buildings
$7.9 \%$
vii. Waste and waste water
$2.8 \%$

Source: Synthesis Report, IPCC, 2007.

According to, ${ }^{7}$ climate change will have disproportional negative impact on developing countries. In many Sub Saharan African countries, the challenge of climate change will not only make achieving the Millennium Development Goals more difficult, but could also threaten some of the progress already made in fighting extreme poverty and disease. The UNFCCC (2007) estimates that climate change risks could cost developing countries up to $19 \%$ of Gross Domestic Product. Similarly, the IPCC Working Group II reported that by 2020 , between 75 million and 250 million people are projected to be exposed to an increase of water stress due to climate change in Africa.

Many countries in the globe will be affected by flooding due to extreme weather. According to, ${ }^{11}$ flooding remains the greatest threat to the United Kingdom posed by climate change, with up to 3.6 million people at risk by the middle of the century.

The Environmental Agency reports that at present 2.3 million homes and 185,000 businesses are at risk of flooding in England and Wales, representing property, land and assets to the value of over $£ 200$ billion. ${ }^{12}$ Studies have shown that the Caribbean and Asian countries will also experience similar trend due to extreme weather. ${ }^{10}$

In Australia, the risk to coastal settlements, infrastructure, industries and ecosystems as a result of climate change could affect up to 247,000 residential buildings with an estimated replacement value of $\$ 63$ billion using 2008 values by $2100 .^{13}$

Climate-induced flooding will also affect the built environment of many developing countries. ${ }^{5,6,14,15}$ This therefore calls for urgent adaptation and mitigation measures to help people cope with climate variability. In Nigeria, the impact of climate-induced flooding will be enormous particularly at the coastal areas where rising sea levels and precipitation are expected to be higher. The issue of flooding is considered more worrisome given that many developing countries, like Nigeria, do not have adequate infrastructure to take care of storm and surface water which could increase the risk of flooding.

\section{The impacts of climate-induced flooding on Nigeria's built environment}

In Nigeria, there are strong indications that the climate is changing. When climate gets warmer, it results to heavy rains, relative sea level rises around most shorelines consequently leading to extreme sea levels being experienced more frequently. Climate change therefore is likely to increase flood risk significantly and progressively over time. ${ }^{16}$ Several cases of flood events abound in Nigeria involving loss of lives and destruction of properties. For instance, in 2012, flooding ravaged 28 out of the 36 states of the country leaving thousands of people dead, properties worth billions of Naira destroyed and about 18,000 injured and over 2.1 million people rendered completely homeless. ${ }^{17}$ Without adaptation plans therefore, climate change is likely to bring ever increasing numbers of accidental deaths and serious injuries and damage to peoples' livelihoods, property, environmental quality and future prosperity.

Some of the impacts of climate-induced flooding on the built environment of Nigeria include: -

i. Erosion of beaches, inundation of coastal lands which could bring about additional costs to protect the affected coastal communities. This will ultimately lead to loss of revenue from tourism in areas such as Lagos state.

ii. More surface runoffs will be expected in the urban areas. This is so because buildings, roads infrastructure and other paved areas within the built environment prevents rainfall from infiltration into the soil. Heavy rain and/or prolonged rainfall will produce very large volumes of surface water, which could overwhelm drainage systems and consequently aggregate the risk of flooding.

iii. Destruction of buildings and other infrastructures in the built environment due to heavy rains and flooding. This could amount to several billions of naira in monetary terms.

iv. High oceans surges will cause water pollution due to salt water intrusion and damage to sewers and sewage system leading to disease outbreak and contamination.

v. Water supply scarcity for urban dwellers due to contamination and pollution can be a major challenge to city dwellers.

vi. Many cities, which had been developed without consideration of the risks that climate change will induce, could become vulnerable for people who live and work in them. For example, the nonavailability of space for evacuation and emergency vehicle access as in the case of slum areas can generate a lot of risks.

vii. Most Urban dwellers will be forced to evacuate their homes as a result of excessive flooding and damage to their houses. This could spur internal migration and exert enormous pressure on government in coping with humanitarian services and emergencies.

viii. There could be internal conflict among the population arising from competition of available facilities including water and food in areas less vulnerable to floods ${ }^{18}$ and other hazards associated with extreme weather.

ix. The damage to homes and urban infrastructure due to increased floods could have knock-on effect on insurance premiums and mental health.

$\mathrm{x}$. There may also be loss of staff working time due to inaccessibility 
of some areas to work places, death of some members of the urban population and ill-health.

xi. Pipelines conveying crude, sewage etc. may be damaged and sanitation could be affected. ${ }^{19}$ Flood waters may be contaminated by the overflow from point sources such as pit latrines, which is a common source of toilet in Nigeria, and toilets linked to sewers may become unusable without water supply. The contamination of urban flood water with faecal material could present a substantial threat of enteric disease.

xii. There could also be some health risk associated with the lack of disaster preparedness to limit the impact of an extreme weather event when it occurs.

xiii. Climate-induced flooding will also impact negatively on agricultural land particularly at the coastal areas due to rising sea level and increased precipitation, which could have large impact on the livelihoods of the inhabitants around those areas.

\section{Recommendations}

Given the impact which climate-induced flooding could have on the built environment, people and livelihoods, urgent actions must be embarked upon now with a view to reducing those impacts through adaptation and mitigation measures.

Below are some recommendations that may be adopted to help people cope with the potential future impacts of climate-induced flooding in Nigeria.

i. Nigeria as well as other developing countries should adopt cleaner and environmentally friendly technologies that will help reduce their per capita carbon dioxide emissions.

ii. Our disaster preparedness machinery should be overhauled and made effective to tackle emergencies arising from flooding and other extreme weather events such as drought, rainstorm etc. investing before disasters is much more efficient and saves considerable spending in emergency aid.

iii. Ongoing development projects should be assessed to ensure that they are not vulnerable to climate change. Adaptation to climate change and variability should be systematically incorporated into new development projects.

iv. Climate change mitigation initiatives should be integrated in development projects and programmes so as to reduce the vulnerability of people to the impact of climate change.

v. Houses should be developed in such a manner that would enable them adapt to extreme weather. This could be achieved by using materials which can withstand heavy rainfall.

vi. Land use regulations should be strictly enforced by all relevant authorities to prevent the construction of houses/buildings along flood plains and areas vulnerable to flooding.

vii. City planning is necessary to ensure that adequate spaces are maintained within residential developments to allow for easy infiltration of surface runoffs during rainfall. Increasing spatial density of urban development could significantly reduce energy use in urban areas and carbon dioxide emissions.

viii. The Ministry of Environment should establish a Risk Assessment Unit which should be sufficiently empowered to undertake vulnerability assessments of the potential impacts of floods and other extreme weather events in all part of the country. Spatial maps illustrating the potential effects of sea level rise on key urban regions particularly in the coastal areas should be prepared.

ix. It is also suggested that government at all level initiate a flood defence budget to tackle the menace of flooding and protect homes from its devastating effects.

\section{Conclusion}

Climate- induced flooding will undoubtedly impact negatively on Nigeria's built environment affecting buildings, roads and other infrastructures. Heavy and prolonged rainfall due to extreme weather will produce volumes of water which could overwhelm drainage systems and consequently aggravate the risk of flooding. It behoves on government therefore to embark on appropriate adaptation ${ }^{20}$ and mitigation measures so as to reduce to impact of climate change in Nigeria. ${ }^{21}$

\section{Acknowledgements}

None.

\section{Conflict of interest}

The author declares no conflict of interest.

\section{References}

1. Satterthwaite D. Climate change and urbanization: effects and implications for urban governance. United nations Expert group meeting on population distribution, urbanization, internal migration and development. New York, USA: United Nations secretariat; 2008.

2. Douglas BC, Kearney MS, Leatherman SP. Sea level rise, history and consequences. International geophysics series 75, Academics Press; 2001;84(34):232.

3. IPCC. Climate change 2007: Synthesis report. Geneva, Switzerland: Intergovernmental panel on climate change; 2007. p. 1-112.

4. Adger N, Aggarwal, P, Agrawala S. Climate change 2007: Impacts, adaptation and vulnerability. Geneva, Switzerland: Intergovernmental panel on climate change; 2007. p. 1-987.

5. Blankespoor B, Dasgupta S, Laplaute B, et al. The economics of adaptation to extreme weather events in developing countries. The World Bank; 2010.

6. Ludwig F, Scheltinga CTV, Verhagen J, et al. Climate change impacts on developing countries. EU accountability. European parliament, Brussels, Northern Ireland: Study paper; 2007.

7. Stern N. The economics of climate change. Cambridge, UK: 2007. p. 1-27.

8. UNFCCC. Climate change: impacts, vulnerabilities and adaptation in developing countries. Bonn, Germany: United Nations Framework convention on climate change; 2007.

9. IPCC. Climate change 2007: Fourth assessment report. Cambridge, UK: Cambridge University press, 2007.

10. Haites E, Pantin D, Attzs M, et al. Assessment of the economic impact of climate change on CARICOM countries. Washington, USA: The world bank technical paper; 2002.

11. Jowit J. Flooding-the greatest threat to the UK; 2012

12. BBC Weather. Climate change from BBC weather centre. BBC; 2012

13. Pederson AN, Mikklesen PS, Nelsen AK. Climate change-induced impacts 
on urban flood risk influenced by concurrent hazards. Journal of flood Risk management. 2012;5(3):203-214.

14. Oxfam. Viet Nam: climate change, adaptation and poor people. Oxford: UK: Oxfam international 2008.

15. Oxfam. Adapting to climate change: what's needed in poor countries, and who should pay. UK: Oxford; 2008.

16. Bariweni PA, Tawari CC, Abowei JFN. Environmental effects of flooding in the Niger delta region of Nigeria. International Journal of Fisheries and Aquatic Science. 2012;1(1):35-46.

17. Ogbanga MM. Impacts of flooding disaster on housing and health in two communities of Ahoada east and west local government areas of rivers state. Nigerian Journal of Agriculture Food and Envirronment. 2015;11(1):44-50.
18. Mc Carthy M. UK told to prepare for mass floods. Environment; 2012.

19. Wilby RL. Adapting to flood risk under climate change. Progress in physical geography. 2012;36(3):348-378.

20. Nicholls R, Brown S, Hanson S, et al. The economics of coastal zone adaptation to climate change. The World Bank. 2010;(1):62.

21. World wire (online) 